\title{
The Spatial Econometric Analysis of Economic Convergence Trend in the Western Region of China--An Empirical Study on the 67 Cities in the "One Belt and One Road" Area
}

\author{
Diwen Jiang \\ School of Economics, Shanghai University, Shanghai, China \\ Email address: \\ chandlerjiang_1205@163.com
}

To cite this article:

Diwen Jiang. The Spatial Econometric Analysis of Economic Convergence Trend in the Western Region of China--An Empirical Study on the 67 Cities in the "One Belt and One Road" Area. Humanities and Social Sciences. Vol. 3, No. 5, 2015, pp. 256-260.

doi: $10.11648 /$ j.hss.20150305.24

\begin{abstract}
The "One Belt and one Road" development strategy is put forward for the development of the western region of China. This paper uses the spatial economic model to do some empirical research on the economic convergence trends in western regions of China. Our results shows that the regional economic growth has a strong space correlation; After considering the spatial factors, the 67 cities have the convergence trend of economic development; beta convergence is more significant when we add the government impact factor, suggesting that the government plays an important role in the economic development convergence trend, but the employment factor's effect on the convergence trend in the development of economy is still in doubt.
\end{abstract}

Keywords: Spatial Autocorrelation, Absolute Convergence, Conditional Convergence, Convergence Trend

\section{中国西部地区经济收敛趋势的空间计量分析一一基于“一带一路” 中国西部67个地级市的实证研究}

\author{
蒋帝文 \\ 经济学院, 上海大学, 上海, 中国 \\ 邮箱 \\ chandlerjiang_1205@163.com
}

\begin{abstract}
摘要: “一带一路” 这一发展战略的提出对于中国西部地区的发展是一个很好的机会。本文运用空间经济模型, 根据 西部地区67个地级市的统计数据对其进行了经济收玫趋势的实证研究。研究表明, 各地区的经济增长有很强的空间自 相关性; 考虑到空间因素之后, 这67个城市的经济发展有绝对 $\beta$ 收玫的趋势; 加入政府影响因子后, $\beta$ 收玫更为显著, 这说明政府在经济发展的收敛趋势起着重要的作用，但是劳动力就业对于经济发展的收敛趋势作用还存在疑问。
\end{abstract}

关键字：空间相关性，绝对收敛，条件收敛，收敛趋势

\section{1. 引言}

长期以来，中国东中西部在地理区位、自然条件、历 史基础等差异性因素作用的基础上, 非均衡经济发展现状
导致的区域间在经济发展水平与速度上的落差, 已成为困 扰中国继续全面发展, 实现共同富裕的一个不容忽视的问 题。中国十八大报告强调指出, 要继续实施区域发展总体 
战略, 充分发挥各地区比较优势, 优先推进西部大开发。 中国更是提出以丝绸之路经济带和 21 世纪海上丝绸之路 为核心的 “一带一路” 战略, 这将使中国经济迎来仅次于 沿海经济带的第二增长极, 必将促进东中西部协调发展, 为中国经济可持续发展提供重要支撑。

本文运用空间经济模型, 根据中国西部67个地级市的 统计数据, 采用 $\beta$ 收玫的分析方法对这 67 个城市进行了经 济收玫趋势的实证分析。研究表明, 各地区的经济增长有 很强的空间自相关性; 考虑到空间因素之后, 这67个城市 的经济发展有绝对 $\beta$ 收玫的趋势; 加入政府影响因子后, $\beta$ 收玫更为显著, 这说明政府对经济发展收玫趋势起着重 要的作用, 但是劳动力就业对于经济发展的收玫趋势作用 还存在疑问。

本文结构安排如下, 第二部分是关于经济发展收玫趋 势的文献综述, 第三部分是介绍 $\beta$ 收玫的理论基础, 第四 部分是空间相关性分析, 第五部分是实证分析, 最后是相 关结论。

\section{2. 文献综述}

关于地区经济收玫趋势的研究, 学者采用不同方法对 不同的数据资料进行了大量的收敛性分析研究。

不少学者利用经济增长的收敛性假说对不同的国家 和地区进行了大量的实证分析 (Baumo1, 1986; Barro and Sala-i-Mrtin, 1992; Pfaffermayr, 2009; Prochniak 和Witkowski, 2013）。例如, Baumol在1986年的时候就发 现人均劳动产出的收玫性, 一个国家的生产率与其平均增 长率有一个很强的负相关关系。之后 Barro 和 Sala-i-Mrtin (1992) 研究了条件收玫问题, 认为各个国家 经济增长的均衡水平根据各国资源禀赋或者文化差异而 有所不同。

蔡昉等 (2000) 从经验上考察中国地区经济增长中存 在着俱乐部趋同以及条件趋同现象; 徐现祥等 (2004) 采 用趋同分析的标准方法, 研究发现中国城市经济增长存在 绝对 $\beta$ 趋同; 陈安平等 (2004) 运用时间序列分析法, 从 一个新的视角研究了中国地区内和地区间经济增长的收 玫性, 实证结果表明, 东部和西部地区内的经济增长具有 收玫性, 而中部地区内和三大地区间的经济增长却不存在 收敛趋势; 李光泗等 (2008) 利用收敛分析框架研究技术 引进对经济收玫的影响, 认为技术引进更有助于实现地区 经济收敛; 刘梦琴（2012）根据经济收敛模型对武汉城市 圈的经济增长的收玫性进行了实证研究, 发现武汉城市圈 经济增长不存在绝对 $\beta$ 收玫, 但是存在条件 $\beta$ 收敛; 杨帆 （2013）在全样本检验的基础上发现, 东亚经济增长表现 出明显的俱乐部收玫特征, 东北亚地区区域内贸易对地区 经济收玫具有推动作用, 而东南亚区域内贸易与经济玫散 程度之间不存在明显的因果关系; 黄安胜 (2014) 通过研 究认为, 发达地区生产要素投入的增加, 将加剧区域经济 增长发散, 而落后地区生产要素投入的增加, 将促进区域 经济增长收敛。

随着空间经济学的发展, 近几年的研究认为空间因素 的影响是不能忽略的, 在研究经济的收玫趋势时有必要将 空间因素考虑在内。例如, 张晓旭等 (2008) 利用三种不
同的空间模型研究了中国各省份人均GDP增长的收玫性, 结果空间误差自回归模型能够满意地解释中国各省级地 区经济增长, 表明地理位置的影响尽管对各地区的经济增 长造成深刻的影响但并没有改变地区经济增长的收敛趋 势。张学良 (2009) 采用统计与空间计量的分析方法, 对 长三角地区进行了区域经济增长收玫性的实证研究, 结果 显示经济增长收敛。Yu和Lee (2012) 采用了空间动态面板模 型的方法探究收玫性的问题。何雄浪等 (2013) 将空间相 关性纳入分析框架, 分析了中国1953-2010年地区经济增长 的绝对收敛性以及考虑财政政策与人力资本影响后的条件 收玫性, 结果证明引入因子后存在条件收玫。朱国忠等

（2014）使用空间动态面板数据模型对各省进行收敛性分 析, 得出了东部地区不收玫, 中西部地区收玫的结论。

通过前人研究可以看出, 前人对于经济收玫问题已经 做了很多的研究, 但是总结前人的研究可以发现, 他们将 研究对象主要是集中在省级层面, 很少涉及地市级, 另一 方面, 中国新提出了 “一带一路” 的新战略, 这对于中国 西部地区的发展将是一个很好的机会, 研究 “一带一路” 所覆盖的城市发展有一定的意义。因此, 本文将 “一带一 路” 战略所涉及到的中国西部地区 67 个地级市作为研究对 象, 分析了这些城市的经济发展收玫趋势, 作为对于这一 领域的补充。

\section{3. 理论基础}

索洛模型是讨论经济增长收玫性的一个很好的依据。 假设生产函数为 $\mathrm{Y}=\mathrm{F}(\mathrm{K}, \mathrm{AL})$, 其中, $\mathrm{Y}$ 表示产量, $\mathrm{K}$ 表示资 本, $\mathrm{A}$ 表示技术, $\mathrm{L}$ 表示劳动力, $\mathrm{AL}$ 被称为有效劳动, 假定 生 产 函 数 规模报 酬不 变, 则 有 $\mathrm{Y} / \mathrm{AL}=\mathrm{F}(\mathrm{K} / \mathrm{AL}, \mathrm{AL} / \mathrm{AL})=\mathrm{F}(\mathrm{K} / \mathrm{AL})$ ，即 $\mathrm{y}=\mathrm{f}(\mathrm{k})$ ，其中 $\mathrm{y}$ 表示人 均产出, $k$ 表示人均资本。人均资本受到储蓄（形成新资 本）和必须的投资（资本消耗）两种因素的影响，假定储 蓄 $\mathrm{s}$ 是收入的一个百分比, 必须的投资取决于人口增长率、 折旧率和技术进步率。一方面资本用于配备新工人, 即为 $\mathrm{nk}$, 一方面资本用于资本折旧, $\mathrm{dk}$ ，一方面资本还用于技 术进步, $\mathrm{gk}$, 其中 $\mathrm{n} 、 \mathrm{~d} 、 \mathrm{~g}$ 分别表示人口增长率、资本折 旧率和技术进步率, 可以得到资本的增加方程为 $\Delta$ $k=s f(k)-(n+d+g) k$, 当经济达到稳态时, $\Delta k=0$, 即 $\mathrm{sf}(\mathrm{k})=(\mathrm{n}+\mathrm{d}+\mathrm{g}) \mathrm{k}$ 。

设 $r_{k}$ 代表人均有效资本的增长率, 则 $r_{k}=\Delta \mathrm{k} / \mathrm{k}=$ $(\mathrm{sf}(\mathrm{k}) / \mathrm{k})-(\mathrm{n}+\mathrm{d}+\mathrm{g})$, 对人均有效资本的增长率求导可 得, $\mathrm{dr}_{\mathrm{k}} / \mathrm{dk}=\mathrm{s} / \mathrm{k}[(\mathrm{df} / \mathrm{dk})-(\mathrm{f} / \mathrm{k})]$, 由于生产函数的凸性, 所以小于 0 。也就是说, 若 $\mathrm{k}$ 更高, 那么人均有效资本的增 长率越低, 同样, 可以看出, 技术进步率越高, 人均有效 资本的增长率越低, 从而那些人均资本初始值较低的国家 拥有更高的资本增长率，从而国民收入的增长速度更快。 在长期, 经济落后的国家会赶上经济发达的国家, 即经济 增长率和初始经济水平成负向关系, 这体现了经济增长收 敛的含义。

这里 $\beta$ 收玫又分为绝对 $\beta$ 收玫和条件 $\beta$ 收玫。绝对 $\beta$ 收玫是不考虑任何的影响因子, 仅有初始经济水平一个因 变量, 而条件 $\beta$ 收玫含有其他的影响因子。 


\section{4. 空间相关性分析}

随着新经济地理学的发展, 已经有很多的学者使用空 间的方法对问题进行研究, 潘文卿 (2012) 指出, 考虑到 “地理学第一定律”, 空间相关性是我们不能忽略的因素, 因此我们要考虑空间相关性。我们通常用Moran I指数来 描述属性值在整个区域的空间相关性。Moran I指数计算 公式为:

$$
\operatorname{MoranI}=\frac{n \sum_{i=1}^{n} \sum_{j=1}^{n} w_{i j}\left(x_{i}-\bar{x}\right)\left(x_{j}-\bar{x}\right)}{\sum_{i=1}^{n} \sum_{j=1}^{n} w_{i j} \sum_{i=1}^{n}\left(x_{i}-\bar{x}\right)^{2}}=\frac{\sum_{i=1}^{n} \sum_{j=1}^{n} w_{i j}\left(x_{i}-\bar{x}\right)\left(x_{j}-\bar{x}\right)}{S^{2} \sum_{i=1}^{n} \sum_{j=1}^{n} w_{i j}}
$$

通常将Moran I解释为一个相关系数, 取值范围在 -1 到1之间， $0<$ Moran $I<1$ 表示正的空间自相关, Moran $I=0$ 时表示不存在空间相关性， $-1<$ Moran $\mathrm{I}<0$ 表示负的空间自 相关。

我们利用GeoDa软件计算出来这西部 67 个城市人均 GDP的全局空间自相关。如下表所示:

表1 Moran I。

\begin{tabular}{llll}
\hline 年份 & $\mathrm{I}$ & $\mathrm{P}$ & $\mathrm{Z}$ \\
\hline 2002 & 0.219298 & 0.002 & 4.5345 \\
2003 & 0.281364 & 0.001 & 4.9887 \\
2004 & 0.253125 & 0.001 & 4.8320 \\
2005 & 0.215449 & 0.003 & 3.9261 \\
2006 & 0.211179 & 0.004 & 3.8035 \\
2007 & 0.202462 & 0.008 & 3.5075 \\
2008 & 0.230589 & 0.004 & 3.4302 \\
2009 & 0.235382 & 0.002 & 3.6973 \\
2010 & 0.20761 & 0.002 & 3.4998 \\
2011 & 0.218688 & 0.005 & 3.3856 \\
2012 & 0.219092 & 0.003 & 3.5059 \\
\hline
\end{tabular}

(数据来源于中国城市统计年鉴)

根据上表, 空间Moran I指数均大于 0 , 且通过显著性 检验，这说明了这67个市经济发展之间存在着空间自相关 性。因此我们分析的时候再只利用简单的OLS回归方法得 到的结果将会不准确。

这些城市经济增长表现出明显的空间相关性, 发展快 的地区因为有更好的技术、更好的资本、更好的劳动力而 发展的更快，因为知识、技术的外溢性，发展快的地区同 时也能够带动周边地区经济的快速发展。当前, 因为中国 国土面积广阔, 深刻的历史、地理背景以及 “让一部分先 富起来, 先富带动后富” 等的一系列政策安排, 使得中国 东中西部地区的发展极不协调。这种不协调的区域经济发 展水平差距拉开之后, 经济系统空间相关性对区域经济发 展的作用便可忽视, 历史上经济增长能力较强的区域后续 发展也很快; 相反, 历史上经济增长能力较弱的区域因生 产因素不断流出而很容易落入贫困落后的陷阱, 最终形成 强者更强、弱者更弱的累积循环（何雄浪等，2013）。

\section{5. 实证分析}

\section{1. 变量选取及数据处理}

本文的数据均来自中国城市统计年鉴, 时间跨度为 2003年到2013年，研究对象为 “一带一路” 战略所覆盖的 67 个西部城市 ${ }^{1}$ 。根据前人的研究, 人均GDP通常能够表 示一个地区经济的发展水平, 因此本文选取 2002 年到 2012 年的人均GDP, 通过计算出每一年的人均GDP增长率作为模 型的因变量, 用 $\mathrm{g}_{\mathrm{it}}$ 表示。本文将上一年的人均GDP作为期 初经济发展水平, 用 $\mathrm{y}_{\mathrm{i}, \mathrm{t}-\mathrm{1}}$ 表示。为了研究政府对地区经济 收玫趋势的影响, 本文选取2003年到2012年的政府财政内 支出数据, 作为影响因子来研究条件 $\beta$ 收玫, 用gov来表 示。同样, 为了研究劳动力对地区经济收玫趋势的影响, 我们采用2003年到2012年的年末劳动力就业人数作为影 响因子来研究条件 $\beta$ 收玫, 用hum来表示; 同时将gov 、hum 都是进行取对数处理, 变量的统计性描述见表 2 :

表2 变量描述性统计。

\begin{tabular}{llllll}
\hline Variable & Obs & Mean & Std. Dev. & Min & Max \\
\hline zz1 & 670 & 0.184 & 0.127 & -0.554 & 1.745 \\
ln2002 & 670 & 8.637 & 0.623 & 7.415 & 11.04 \\
gov & 670 & 13.28 & 0.991 & 10.41 & 17.23 \\
human & 670 & 2.953 & 0.767 & 1.399 & 6.753 \\
\hline
\end{tabular}

\section{2. 模型估计}

绝对收玫模型主要关注经济收敛是否存在, 并不区分 收玫的原因, 而条件收玫模型则需要引入其他控制变量。 本文中, 我们根据前人的研究, 采用空间自回归模型 (SAR) 和空间误差模型 (SEM) 来进行实证分析。

\subsection{1. 空间自回归模型（SAR）}

在空间自回归模型中, 变量的空间相关关系由外生的 空间滞后变量 $\sum \mathrm{w}_{i j} g_{i j}$ 来反映。模型设定如下:

i绝对收敛:

$$
\mathrm{g}_{i t}=\alpha+\beta_{1} \ln y_{i, t-1}+\rho \sum w_{i j} g_{i t}+\mu_{i}+\varepsilon_{i t}
$$

其中， $\mathrm{y}_{\mathrm{i}, \mathrm{t}-1}$ 表示期初经济发展水平， $\rho$ 表示空间自回 归系数, $\mathrm{w}_{\mathrm{i} j}$ 表示空间权重矩阵的第 $\mathrm{i}$ 行第 $\mathrm{j}$ 列。这里, 我们 采用邻接矩阵的方法构建空间权重矩阵, 即相邻则 $\mathrm{w}_{\mathrm{ij}}=1$, 不相邻则 $W_{i j}=0$ 。 $\mu_{i}$ 为区域 $i$ 的个体效应。

ii条件收敛:

1分别为西安市、铜川市、宝鸡市、咸阳市、渭南市、延安市、汉中市、 榆林市、安康市、商洛市、兰州市、嘉峪关市、金昌市、白银市、天水 市、武威市、张掖市、平凉市、酒泉市、庆阳市、西宁市、银川市、石 嘴山市、吴忠市、固原市、乌鲁木齐市、克拉玛依市、重庆市、成都市、 自贡市、攀枝花市、沾州市、德阳市、绵阳市、遂宁市、内江市、乐山 市、南充市、眉山市、宜宾市、广安市、达州市、雅安市、巴中市、资 阳市、昆明市、曲靖市、玉溪市、保山市、昭通市、丽江市、普洱市、 临沧市、南宁市、柳州市、桂林市、梧州市、北海市、防城港市、钦州 市、贵港市、玉林市、百色市、贺州市、河池市、来宾市及崇左市。 
$\mathrm{g}_{i t}=\alpha+\beta_{1} \ln y_{i, t-1}+\beta_{2}$ gov $+\beta_{3} h u m+\rho \sum w_{i j} g_{i t}+\mu_{i}+\varepsilon_{i t}$ 子。

其中, gov、hum表示上文提到的政府和劳动力影响因

\subsection{2. 空间误差模型 (SEM)}

当空间关联通过被模型解释变量忽略了的自变量传 递时, 可以假设空间关联通过误差过程产生。模型设定如 下:

i绝对收敛:

$$
\mathrm{g}_{i t}=\alpha+\beta_{1} \ln y_{i, t-1}+\mu_{i}+\varepsilon_{i t}
$$

$$
\varepsilon_{\mathrm{i} t}=\lambda \sum w_{i j} \varepsilon_{j t}+v_{i t}
$$

其中, $\lambda$ 表示空间相关系数。 ii条件收敛:

$$
\begin{gathered}
\mathrm{g}_{i t}=\alpha+\beta_{1} \ln y_{i, t-1}+\beta_{2} g o v+\beta_{3} h u m+\mu_{i}+\varepsilon_{i t} \\
\varepsilon_{\mathrm{i} t}=\lambda \sum w_{i j} \varepsilon_{j t}+v_{i t}
\end{gathered}
$$

\begin{tabular}{|c|c|c|c|c|c|c|c|c|}
\hline & SAR (re) & & SEM (re) & & $\operatorname{SAR}(\mathrm{fe})$ & & $\operatorname{SEM}(\mathrm{fe})$ & \\
\hline & 绝对收玫 & 条件收敛 & 绝对收玫 & 条件收玫 & 绝对收玫 & 条件收玫 & 绝对收玫 & 条件收玫 \\
\hline$\beta_{1}$ & $\begin{array}{l}-0.0129 * \\
(-2.16)\end{array}$ & $\begin{array}{l}-0.0205 * * \\
(-2.80)\end{array}$ & $\begin{array}{l}-0.0211 * * \\
(-2.84)\end{array}$ & $\begin{array}{l}-0.0226 * * \\
(-2.91)\end{array}$ & $\begin{array}{c}-0.0140 \\
(-1.61)\end{array}$ & $\begin{array}{l}-0.283 * * * \\
(-11.19)\end{array}$ & $\begin{array}{l}-0.0517 * * \\
(-2.88)\end{array}$ & $\begin{array}{l}-0.297 * * * \\
(-11.25)\end{array}$ \\
\hline$\beta_{2}$ & & $\begin{array}{l}0.0220 * * \\
(3.11)\end{array}$ & & $\begin{array}{l}0.0230 * \\
(2.57)\end{array}$ & & $\begin{array}{l}0.197 * * * \\
(11.09)\end{array}$ & & $\begin{array}{l}0.200 * * * \\
(10.70)\end{array}$ \\
\hline$\beta_{3}$ & & $\begin{array}{l}-0.0245 * * \\
(-3.04)\end{array}$ & & $\begin{array}{l}-0.0223 * \\
(-2.40)\end{array}$ & & $\begin{array}{l}0.0143 \\
(0.46)\end{array}$ & & $\begin{array}{l}0.0262 \\
(0.84)\end{array}$ \\
\hline$\rho$ & $\begin{array}{l}0.389 * * * \\
(8.38)\end{array}$ & $\begin{array}{l}0.378 * * * \\
(8.13)\end{array}$ & & & $\begin{array}{l}0.378 * * * \\
(8.16)\end{array}$ & $\begin{array}{l}0.348 * * * \\
(7.77)\end{array}$ & & \\
\hline$\lambda$ & & & $\begin{array}{l}0.402 * * * \\
(8.68)\end{array}$ & $\begin{array}{l}0.377 * * * \\
(8.03)\end{array}$ & & & $\begin{array}{l}0.438 * * * \\
(8.15)\end{array}$ & $\begin{array}{l}0.377 * * * \\
(7.89)\end{array}$ \\
\hline AIC & & & & & -995.4978 & -1107.22 & -1003.684 & -1108.705 \\
\hline BIC & & & & & -981.976 & -1084.683 & -990.1621 & -1086.168 \\
\hline
\end{tabular}

我们采用stata软件, 根据所获得的数据对模型进行 估计检验。估计结果如下表所示:

表3 估计结果。

$\mathrm{t}$ statistics in parentheses $* \mathrm{p}<0.05, * * \mathrm{p}<0.01, * * * \mathrm{p}<0.001$

(经过豪斯曼检验, 豪斯曼统计量为正数, $\mathrm{p}$ 值为 0 , 我们拒绝随机效应的假设, 而采用固定效应模型。根据AIC、BIC指数, 我们选择SEM模型, 故 我们所分析的为最后两列。)

根据估计结果, $\beta_{1}$ 小于 0 , 并且都通过显著性检验, 表明中国西部这67个城市的经济发展在长期有着收敛的 趋势。根据索洛模型, 初始经济水平高的地区经济发展会 被初始经济水平低的地区追赶上, 最终达到一个稳态的水 平，模型的估计结果符合这一理论。

加入政府支出和劳动力影响因子后, $\beta_{1}$ 的符号并没 有改变, 而且绝对值变大, 这表明初始经济水平高的地区 经济增长率会更慢, 而且, 通过检验 $\beta_{1}$ 的显著性提高。 而 $\beta_{2}$ 大于 0 , 并且通过了显著性检验，表明政府采取积极 的财政政策能够促使经济较快发展, 强化了区域经济的条 件收玫性。但是同时值得注意的是，在SEM模型中，劳动 力影响因子并没有通过显著性检验, 说明就业对经济条件 收敛趋势的作用是存在疑问的。另外, 空间自回归系数都 通过了显著性检验, 说明经济的收玫趋势会受到空间因素 的影响。

\section{6. 结论及政策含义}

本文采用空间误差模型对中国 “一带一路” 所涉及的 西部67个地级市的经济发展趋势进行了 $\beta$ 收敛分析。实证 分析表明中国这67个地区的经济发展存在着绝对 $\beta$ 收玫, 加入政府和劳动力影响因子后, $\beta$ 符号没有改变, 而且显 著性增强。政府对于经济发展收敛趋势的作用还是很明显,
相应可能的政策含义是政府在调节经济的协调发展中有 着很重要的作用。但是劳动力就业没有通过显著性检验, 这表明劳动力对于经济发展收敛趋势的作用还存在着疑 问。

本文仅仅是对这67个城市的经济发展收敛趋势做了 一个简单的空间分析，“一带一路”究竟会带给中国西部 这67个城市什么样的机会还有待研究。本人将继续以 “一 带一路” 所涉及的省城、国家为研究对象, 探究这一战略 对于国家西部地区以及整个国家经济的影响。

\section{参考文献}

[1] Barro. R. and X. Sala-i-Martin, “Convergence” , Journal of Political Economy, 1992, 100 (2), 233-251.

[2] Baumol.W. J, 1986, Productivity Growth, Convergence and Welfare: What the Long-Run Data Show[J], American Economic Review, 76, 1072-1085.

[3] Pfaffermayr M. Conditional $\beta$-and $\sigma$-convergence in space: A maximum likelihood approach[J]. regional Science and Urban Economics, 2009, 39(1): 63-78. 
[4] Prochniak M, Witkowski B. Time stability of the beta convergence among EU countries:Bayesian model averging perspective[J]. Economic Modelling, 2013, 30: $322-333$.

[5] Yu. J. and L. Lee, “Convergence:A Spatial Dynamic Panel Data Approach”, Global Journal of Economics, 2012, 1(1), 1-37.

[6] 蔡昉, 都阳. 中国地区经济增长的趋同与差异 $[\mathrm{J}]$. 经济研究, 2000, (10) : 30-37。

[7]陈安平, 李国平. 中国地区经济增长的收玫性: 时间序列的 经验研究 $[J]$. 数量经济技术经济研究, 2004, (11): 31-35。

[8］何雄浪, 郑长德, 杨霞. 空间相关性与我国区域经济增长动 态收敛的理论与实证分析 [J]. 财经研究, 2013(7): 82-95。

[9] 黄安胜, 郑逸芳, 王强强, 许佳贤. 生产要素、区域增长差 异和收敛性 $[\mathrm{J}]$. 经济问题, 2014（11）：112-117。

[10] 刘梦琴. 武汉城市圈经济增长收玫性的实证研究 [J]. 统计 与决策, 2012（4）：126-129。
[11] 李光泗, 徐翔. 技术引进与地区经济收玫 $[J]$. 经济学 (季刊), 2008（4）：983-996。

[12] 潘文卿. 中国的区域关联与经济增长的空间溢出效应 [J]. 经济研究, 2012（1）：54-65。

[13] 杨帆, 滕建州. 东亚贸易自由化与经济收玫关系研究 $[J]$. 经济学家, 2013 (3) : 24-31。

[14] 徐现祥, 李狍. 中国城市经济增长的趋同分析 $[J]$. 经济研究, 2004, (5) : 40-48。

[15] 张晓旭, 冯宗宪. 中国人均GDP的空间相关与地区收敛: 1978-2003[J]. 经济学 (季刊)，2008，（1）：399-414。

[16] 张学良. 中国区域经济收玫的空间计量分析 [J]. 财经研究, 2009, (7) : 100-109。

[17] 朱国忠, 乔坤元, 虞吉海. 中国各省经济增长是否收玫? [J]. 经济学 (季刊)，2014，（3）：1171-1184。 